\title{
EDITORIAL
}

\section{Revista Iberolatinoamericana de Parasitología: Nueva etapa de dos revistas de Parasitología}

Con el presente número, entregamos los dos últimos fascículos del volumen 63 (2008) de Parasitología Latinoamericana. A contar del próximo año nuestra revista se fusionará con la Revista Ibérica de Parasitología, constituyendo un nuevo órgano en donde los especialistas de la Península ibérica y de Latinoamérica tendrán la oportunidad de publicar sus trabajos científicos y entregar sus aportes al perfeccionamiento de los profesionales de la Región.

Este nuevo órgano científico tendrá como nombre REVISTA IBEROLATINOAMERICANA DE PARASITOLOGIA y en su primer año (2009) entregará dos fascículos para aumentarlos a tres en los años siguientes.

Circunstancias de variado orden y naturaleza, han hecho necesaria la fusión de las dos revistas y esperamos que esta nueva sea el producto de la suma y potenciación de lo mejor de cada una de ellas.

En las revistas originales, se han publicado centenares de valiosas contribuciones de autores latinoamericanos, españoles y de otros países del mundo, los que han escrito sobre variados temas de taxonomía, biología y bioquímica de parásitos, aspectos clínicos, inmunológicos, epidemiológicos y control de las diferentes infecciones parasitarias del hombre y de los animales. Este mismo tipo de contenido será mantenido por la Revista Iberolatinoamericana de Parasitología.

La Revista Ibérica de Parasitología y Parasitología Latinoamericana, a fines del año 2008 han publicado 67 y 63 volúmenes respectivamente. Como la Revista Ibérica de Parasitología nació antes, mantendremos esa antigüedad, de tal manera que el primer número de la nueva revista corresponderá al volumen $\mathbf{6 8 .}$

Informados algunos integrantes de la Federación Latinoamericana de Parasitólogos (FLAP) de la fusión de ambas revistas, se recibieron comentarios muy favorables.

Los colaboradores, lectores, distribuidores y subscriptores deberán dirigirse y mantener su correspondencia con Revista Iberolatinoamericana de Parasitología. a Casilla 9183, Santiago 1, Chile, o con Fax (56-2) 5416840.

Para agilizar la edición de la revista, los autores de los trabajos, deberán enviar por correo sus artículos científicos, grabados en un $\mathrm{CD}$, en Word 6.0 o superior. La modalidad, estilo y diagramación de los trabajos se darán a conocer en página interiores de la nueva revista o Internet www.scielo.cl. Por el momento es permitido escribir los artículos al estilo que se indicaba para cada revista.

Nuestro equipo está entusiasmado con la nueva revista y nos anima a proseguir con mayor responsabilidad y seriedad su tarea de editarla. Sin embargo, el desafío que implica mantener su continuidad y perfeccionamiento no es sólo tarea de nosotros. Desde ya esperamos el apoyo generoso de los parasitólogos latinoamericanos para que nos permitan cumplir con el compromiso que hemos adquirido. 